\title{
O CONTEXTO ORGANIZACIONAL E SEUS REFLEXOS NO DESENVOLVIMENTO DE COLEÇÕES: UM ESTUDO À LUZ DAS DIFERENTES MODALIDADES DE BIBLIOTECAS
}

\author{
Jorge Santa Anna ${ }^{1}$ \\ jorjao20@yahoo.com.br
}

\begin{abstract}
Resumo: A formação e o desenvolvimento de coleções em bibliotecas constituem um processo que vem sofrendo alterações ao longo dos tempos e que deve ser gerido com criteriosidade, haja vista viabilizar qualidade aos materiais incorporados ao acervo bibliográfico. Mesmo havendo diversas recomendações propostas pela literatura quanto às atividades de formar e desenvolver coleções, a realidade das bibliotecas costuma ser divergente em alguns aspectos. Portanto, este estudo objetiva analisar as atividades imbuídas nesse processo, realizadas em quatro distintas bibliotecas, contemplando as modalidades: pública, escolar, especializada e universitária. Pretende-se, através de análise comparativa de dados, apresentar a dispersão de procedimentos realizada na formação e desenvolvimento das coleções das respectivas bibliotecas analisadas. Através de entrevista aos gestores dessas unidades, constatou-se que em cada modalidade de biblioteca, ou em cada contexto organizacional/institucional, os procedimentos que sustentam o processo de formar e desenvolver coleções são diferenciados, sendo que, boa parte das atividades realizadas pela biblioteca especializada e universitária está condizente com as recomendações propostas pela literatura, enquanto que na biblioteca pública e escolar, a realidade é bem destoante. Infere-se que, mesmo sendo influenciadas pelo contexto organizacional/institucional, faz-se imprescindível o estabelecimento de uma política para formar e desenvolver coleções, de modo a facilitar a gestão das coleções e o desenvolvimento equilibrado do acervo.
\end{abstract}

Palavras-chave: Acervo bibliográfico. Formação e desenvolvimento de coleções. Gestão de coleções. Política de desenvolvimento de coleções.

\section{INTRODUÇÃO}

O paradigma da biblioteca contemporânea é prover informação de qualidade de acordo com diversas necessidades, atendendo as expectativas de diferentes usuários. Para tanto, as bibliotecas utilizam das informações armazenadas em coleções bibliográficas, fornecendo acesso ou posse a documentos, estando esses revestidos de diferentes suportes ou recursos que materializam a informação.

No entanto, os documentos agrupados em coleções que, por sua vez formam os acervos das bibliotecas, a fim de atingirem a posição de objetos de uma coleção bibliográfica requerem um conjunto de

\footnotetext{
${ }^{1}$ Possui graduação em Biblioteconomia pela Universidade Federal do Espírito Santo (UFES, 2012). Atualmente, é instrutor de cursos sobre Normalização e Editor de Textos para Trabalhos Acadêmicos e Redação Oficial no Departamento de Pessoas da UFES; mestrando do Programa de Pós-Graduação em Gestão e Organização do Conhecimento da Universidade Federal de Minas Gerais (UFMG); bolsista do projeto elaboração e implantação de uma política de periódicos e construção do portal de periódicos de Minas Gerais, financiado pela Fundação de Amparo à Pesquisa de Minas Gerais (FAPEMIG); membro do grupo de pesquisa Informação e sistemas de informação: Estudos de usuários e usos, financiado pelo CNPQ; atua no ramo da consultoria informacional, com foco em normalização, estruturação e revisão de projetos e pesquisas acadêmico-científicas; ministra aulas, cursos e treinamentos sobre metodologia científica e leciona nos cursos de Biblioteconomia e Administração; e é revisor e assessor do periódico Pró-Discente do Programa de Pós-Graduação em Educação da UFES.
} 


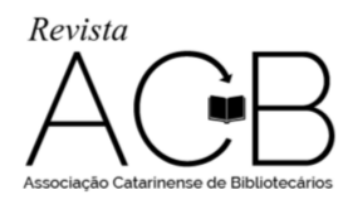

procedimentos gerenciados prévia e continuamente por profissionais competentes nessa função, haja vista, agregar valor ao acervo.

Os acervos bibliográficos existentes nas bibliotecas não constituem um simples amontoado de livros, mas, ao contrário, a lógica estabelecida na representação e guarda documental, assim como o fluxo de entrada e saída de documentos da coleção permite entendê-la como um sistema dinâmico, integrado e relacional. E é essa fluidez que viabiliza o crescimento da coleção e de toda a biblioteca, que, conforme Ranganathan (2009), essa unidade deve constituir um organismo em crescimento.

Assim, é preciso estabelecer critérios ou parâmetros científicos para que a coleção não se torne inutilizável, sobretudo com a explosão bibliográfica dos últimos tempos. Nesses novos tempos, se as coleções não forem gerenciadas, levando em consideração o fator qualidade, por conseguinte, satisfação do usuário, corre-se o risco das coleções tornarem-se abarrotadas (VERGUEIRO, 1993) e a biblioteca adquirir aspecto de depósito.

É nessa discussão que o desenvolvimento de coleções, também denominado de gestão das coleções ou gestão de estoques de informação, destacou-se nos últimos anos, embora sua prática date de tempos antigos. Gerir coleções, na atualidade, passou a ser um compromisso do profissional que deseja garantir a permanência da biblioteca na sociedade, mantendo nela a função de gerenciadora na produção de conhecimento e no desenvolvimento social.

Ao longo do tempo, a forma de acumulação dos materiais nos acervos das bibliotecas foi se modificando, sobretudo com o crescimento da produção bibliográfica, iniciada a partir da evolução dos suportes eletrônicos. Assim, com o crescimento exponencial da produção bibliográfica e com o desenvolvimento tecnológico, novos procedimentos foram (e são) utilizados pelos bibliotecários. Isso ocorreu de forma evolutiva, tornando essas atividades cada dia mais necessárias (WEITZEL, 2012). De acordo com Correa e Santos (2015), assistiu-se, em períodos remotos, à formação de acervos, passando ao desenvolvimento de coleções, gestão de coleções, para, na atualidade, com o surgimento das coleções digitais, surgir práticas mais ampliadas, a gestão de estoques de informação.

Assim, independente da nomenclatura que receba, as práticas de gerir coleções requer o estabelecimento de critérios, padrões e metodologias visando a permitir o crescimento racional do acervo (WEITZEL, 2006). Para isso, através de procedimentos padrões, contidos em política específica, levando em conta as necessidades dos usuários da coleção, institui-se procedimentos uniformes, com vistas a permitir essa racionalidade (MIRANDA, 2007).

Embora a literatura especializada da área confirme a necessidade e importância da uniformidade dos processos, podendo as unidades compartilharem procedimentos, métodos, técnicas e experiências, a realidade 


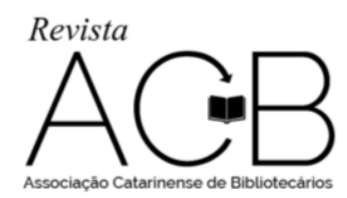

de cada unidade de informação é bem singular. Nota-se, na prática, atividades bibliotecárias plurais, no que se refere ao desenvolvimento de suas coleções, ou seja, o processo de formação e desenvolvimento de coleções realiza-se de diferentes formas, principalmente quando se compara diferentes modalidades de biblioteca, conforme relatado por Vergueiro (1993, p.18): “[...] A adequação do desenvolvimento de coleções às características da organização bibliotecária em que se realiza parece ser uma tendência quase dominante $[\ldots] "$.

Com base nesse relato a respeito do processo de formação e desenvolvimento de coleções, este estudo objetiva analisar as atividades imbuídas nesse processo, realizadas em quatro distintas bibliotecas, contemplando as modalidades: pública, escolar, especializada e universitária. Pretende-se, através de análise comparativa de dados, apresentar a dispersão de procedimentos realizada na formação e desenvolvimento das coleções das respectivas bibliotecas analisadas.

Para tanto, o estudo apresenta a seguinte estrutura: discussão teórica a respeito das principais características e conceituações relacionadas à gestão de coleções; reflexão acerca da interferência do contexto organizacional no processo de formar e desenvolver coleções em bibliotecas; e, ao final, demonstra a realidade de diferentes modalidades de bibliotecas, considerando o instrumento de coleta de dados, formado por sete perguntas que investigavam alguns aspectos em relação às atividades de formar e desenvolver coleções bibliográficas.

\section{GESTÃO DE COLEÇÕES: PRINCIPAIS CONCEITOS E CARACTERÍSTICAS}

As coleções bibliográficas que compõem os acervos das bibliotecas são formadas por objetos ou itens que materializam algum tipo de informação e que passaram por um conjunto de procedimentos, antes de serem incorporados às coleções, tendo esses métodos a função de tornar os itens disponíveis para serem acessados e utilizados (SANTA ANNA, 2015).

Os procedimentos que compõem os processos de preparação do objeto informacional são dos mais variados. Trata-se de atividades como o estudo dos usuários da biblioteca, a elaboração de manuais de serviços, pautados em políticas específicas, as atividades de catalogação, indexação e classificação, dentre outros. Esses procedimentos estão imbuídos em diversas funções interligadas, as quais compõem as funções bibliotecárias (MACIEL; MENDONÇA, 2006).

Atividades específicas de aquisição dos itens no mercado editorial, assim como a avaliação desses objetos quanto a sua usabilidade, tendo em vista, sua permanência, remanejo ou retirada definitiva do acervo, 


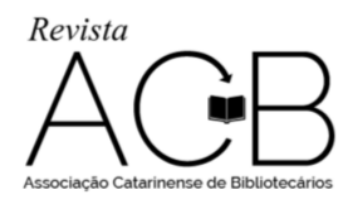

O contexto organizacional e seus reflexos no desenvolvimento de coleções: um estudo à luz das diferentes modalidades de bibliotecas - Jorge Santa Anna

em linhas gerais, são algumas das atividades que compõem o processo ou função, denominado de formação e desenvolvimento de coleções (VERGUEIRO, 1989).

Portanto, a formação e o desenvolvimento de coleções constituem um conjunto de atividades relacionadas entre si, o qual visa permitir que os acervos bibliográficos cresçam de forma mais controlada e racional, de modo a atender as diferenciadas necessidades dos usuários. Assim, a coleção tende a se tornar atualizada e com material de qualidade, uma vez que atenderá as necessidades do público alvo da biblioteca, cumprindo com seus objetivos institucionais (VERGUEIRO, 1989).

Para Miranda (2007a), o desenvolvimento de coleções é um processo que visa estabelecer critérios para que o acervo cresça ordenadamente, de forma sistematizada e relacional. Essa necessidade tem se tornado ainda mais visível a partir do crescimento da indústria editorial e com o uso das tecnologias computacionais. Portanto,

Com a explosão da informação e a evolução das tecnologias da informação, a produção e circulação do conhecimento aumentaram vertiginosamente, tendo como consequência: a impossibilidade de manter uma coleção completa e auto-suficiente; a impossibilidade de atender todas as demandas e necessidades informacionais da clientela com recursos próprios, em razão dos orçamentos escassos. No entanto, torna-se essencial a realização de um planejamento eficiente no tocante ao crescimento dos acervos, e assim, entra em ação o processo de desenvolvimento das coleções (MIRANDA, 2007a, p. $5)$.

Ademais, para a referida autora, a formação e desenvolvimento da coleção representam uma forma de gerenciar ou administrar as coleções bibliográficas. De forma similar, Vergueiro (1993) afirma que o desenvolvimento de coleções é um processo cíclico, contínuo, o qual visa instituir procedimentos padrões para a gestão dos recursos informacionais.

Vergueiro (1993) cita diferentes formas de gestão que podem ser utilizadas pelas bibliotecas. De modo geral, o desenvolvimento de coleções é permeado por diferentes etapas, as quais são realizadas de forma integrada, tendo uma etapa interferência no desenvolver da outra. De modo geral, segundo Miranda (2004), desenvolver coleções implica em sistematizar e criar procedimentos para seleção, aquisição, avaliação e desbastamento do acervo.

No entendimento de Wortman (1989), o processo da formação e desenvolvimento de coleções descreve todas as atividades de seleção, aquisição e manutenção de coleções em uso. Essas atividades precisam ser tratadas como partes inter-relacionadas de um complexo programa de administração de coleções. O autor enfatiza que os bibliotecários precisam pensar holisticamente sobre suas coleções, identificando conexões entre os vários elementos da coleção e as atividades de administração. 


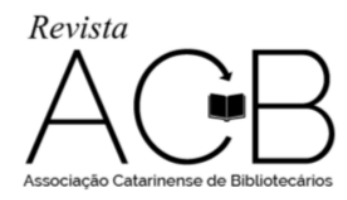

Vergueiro (1993) destaca o desenvolvimento de coleções como um processo dinâmico, composto por atividades adversas e inter-relacionadas, devendo essas atividades serem norteadas por política específica, a qual determinará os critérios a serem considerados para que haja qualidade na seleção dos itens.

A literatura da área estabelece diferentes modelos para gerenciar as coleções. A escolha por um ou outro modelo deverá considerar os objetivos da instituição, bem como o perfil da comunidade atendida, e, principalmente, considerar aspectos ligados à cultura organizacional (VERGUEIRO, 1993).

Em linhas gerais, os modelos mais destacados na literatura, tendo em vista, a consolidação de uma efetiva gestão de coleções, diz respeito ao modelo estruturalista, defendido por James Baughman; o modelo hieráquico, proposto por Hendrik Edelman; e, por fim, o modelo holístico, de Edgard Evans (VERGUEIRO, 1993).

Defende Santa Anna (2014) que os modelos pautados em hierarquias são mais adaptados a pequenas unidades de informações, em contextos isolados. Ao contrário, o modelo estruturalista de Baughman preza pela interação entre as etapas do processo. Semelhantemente, o modelo de Evans adota a estrutura sistêmica. Nesses dois últimos modelos, infere-se que eles se desenvolvem em meio a uma gestão compartilhada.

O modelo holístico, ao defender a necessidade da integração da biblioteca com o contexto social e organizacional em que está inserida, assemelha-se a um guarda-chuva, em que, cada uma das "varetas" corresponde a uma etapa do processo. Assim, há a interdependência das diversas etapas que constituem o processo de desenvolvimento de coleções, que são: estudo da comunidade, política de seleção, seleção, aquisição, desbaste e avaliação (WEITZEL, 2006).

De qualquer forma, o processo de formação e desenvolvimento de coleções deve revestir-se de procedimentos administrativos, o que efetiva a prática da gestão em meio a essas importantes atividades desenvolvidas em acervos bibliográficos físicos ou eletrônicos (SANTA ANNA, 2015).

Em conformidade com a pesquisa do autor supracitado, na atualidade, as coleções precisam ser gerenciadas, ou seja, o bibliotecário deve considerar, a priori, a unidade de informação como uma organização conduzida por processos de gestão. Nessa mesma linha de raciocínio está a tese de Correa e Santos (2015), para quem, a gestão das coleções requer a ampliação de práticas, uma vez que os documentos incorporados nas coleções adquiriram novas formas de serem compartilhados através de canais informatizados.

Portanto, a gestão dos estoques de informação não exige conhecimento apenas dos materiais físicos que são adquiridos pelas bibliotecas, mas também, deve permear o ambiente eletrônico, tendo o profissional que administrar novos fazeres que compõem o ambiente das bibliotecas digitais. Os estoques de informação são arquitetados em diferentes suportes, o que provoca novos desafios e tendências para o bibliotecário 


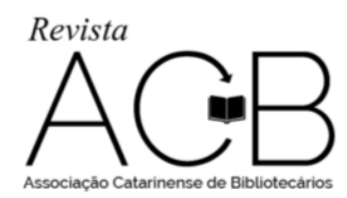

gestor e para todos os processos de trabalhos que permeiam a concretização, avaliação e permanência dos acervos bibliográficos (CORREA; SANTOS, 2015).

Não resta dúvida de que, em meio à administração de recursos informacionais, assim como apontou Vergueiro (1993), é necessário estabelecer a política, a qual garantirá uniformidade aos processos de trabalho, parâmetros e critérios para a seleção, desbaste e descarte de itens, dentre outras normas que são instituídas a fim de serem seguidas, visando controle e constante monitoramento.

A respeito da política de desenvolvimento de coleções, Weitzel (2006, p. 18) enfatiza que ela representa "[...] um instrumento importante para desencadear o processo de formação e crescimento de coleções, constituindo-se num documento formal elaborado pela equipe responsável pelas atividades que apoiam o processo de desenvolvimento de coleções como um todo". Portanto, faz-se necessário o estabelecimento desse documento, de forma que as decisões a serem tomadas estejam oficializadas formalmente, garantindo segurança e uniformidade aos processos e decisões.

\section{GESTÃO DE COLEÇÕES E A INTERFERÊNCIA CONTEXTUAL}

Mesmo sendo imprescindível o estabelecimento e cumprimento da política de formação e desenvolvimento de coleções, é importante destacar que, cada unidade de informação reflete em seus processos de trabalho, a ambiência interna e externa em que está inserida, o que requer estudos detalhados das condições contextuais e estruturais, antes de se estabelecer as normas e procedimentos (MACIEL; MENDONÇA, 2006).

Mesmo sendo visíveis essas questões específicas em que cada unidade está inserida, é comum observar alguns procedimentos similares que são realizados rotineiramente em algumas bibliotecas, sobretudo aquelas pertencentes a uma mesma modalidade. Assim, Vergueiro (1989) defende que o desenvolvimento de coleções é um trabalho de planejamento, ininterrupto e cíclico que serve a uma determinada comunidade; uma atividade rotineira das bibliotecas que passa por várias etapas; é um processo homogêneo que se desenvolve em todas as bibliotecas de acordo com os objetivos de cada uma.

No entanto, é errôneo considerar que as atividades, por serem semelhantes, requerem o estabelecimento de processos de trabalho homogêneos. É preciso considerar que mesmo havendo similaridade, não quer dizer que a forma como a coleção é desenvolvida seja repetida nas diversas unidades de informação, pois existem fatores específicos e adversos que interferem em cada uma delas (SANTA ANNA, 2015). 


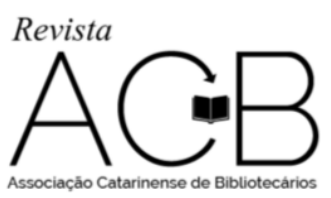

Considerando a afirmação do autor supracitado, dialogamos com Maciel e Mendonça (2006, p. 21) quando mencionam que:

O nível de complexidade das atividades de aquisição naturalmente varia conforme as características das instituições onde ocorrem. Diferentes estruturas administrativas, e diferentes objetivos, exigirão procedimentos também diferenciados. Em bibliotecas universitárias, por exemplo, costumam ocorrer de modo diferente do que em uma biblioteca pública. Em qualquer dos casos, no entanto, o importante é a preocupação com a eficiente organização do processo de aquisição, de modo a garantir que o item selecionado ingresse no acervo no menor tempo e ao menos custo.

Nota-se que o fator primordial que sustenta o processo de formação e desenvolvimento da coleção diz respeito às necessidades dos usuários que recorrem à unidade de informação. Isso também é discutido no estudo de Miranda (2007b), ao mencionar as particularidades das bibliotecas especializadas, as quais servem demandas organizacionais.

Segundo Miranda (2007b, p. 87), “A gestão da coleção é fator fundamental à plena consecução dos objetivos das bibliotecas [...]". Por isso, o contexto (ambiente interno e externo onde a biblioteca está inserida) representa um dos maiores fatores que interfere na forma como as coleções bibliográficas devem ser formadas e desenvolvidas. Santa Anna (2015) também confirmou, através de pesquisa em diferentes modalidades de bibliotecas, que cada uma estabelece os processos de trabalho de acordo com os objetivos a que se propõe e sofrem interferências de questões políticas, econômicas, sociais, culturais, enfim, do ambiente interno e externo que permeia a unidade de informação.

Portanto, grande parte da literatura é unânime ao considerar as questões contextuais ${ }^{2}$ como fator de maior interferência, tendo como finalidade principal atender demandas específicas. Assim, a formação, desenvolvimento e organização do acervo devem ser encarados “[...] como um processo permanente no qual as atividades de seleção, aquisição e avaliação de materiais devem permanecer em contínua sintonia com as necessidades de informação da comunidade de usuários [...]” (MIRANDA, 2007b, p. 87, grifo nosso).

A autora cita nesse mesmo estudo, as especificidades das bibliotecas especializadas, em que devem atender às necessidades de informação das organizações ou empresas às quais se encontram subordinadas. Em outro estudo, Miranda (2007a) menciona as complexidades existentes no cotidiano das universidades, as quais se colocam a serviço da pesquisa, do ensino e da extensão. Logo, as bibliotecas dessas instituições de ensino devem atender os diferentes usuários da universidade que são: servidores, professores, pesquisadores e alunos.

\footnotetext{
2 Considera-se como contexto, no âmbito deste estudo, o ambiente interno (da organização ou instituição mantenedora) quanto externo (a comunidade) em que a unidade de informação está inserida e que, considerando as forças oriundas desses ambientes, há interferências na forma como os serviços e produtos bibliotecários devam ser realizados.
} 


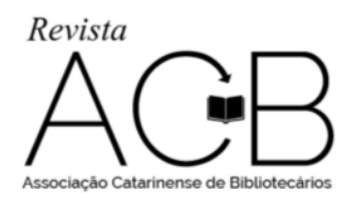

Diferentemente das bibliotecas especializadas e universitárias, as bibliotecas escolares, por exemplo, estão submetidas ao sistema de ensino básico, logo, devem-se colocar a serviço da educação básica e fundamental oferecida nessas unidades educacionais. Por isso, o processo de formar e desenvolver coleções de uma biblioteca escolar é específico do contexto escolar, devendo ser selecionados itens, cujos conteúdos sejam claros, exatos, e dentro das características da unidade de informação, e principalmente dentro do conteúdo dos programas das disciplinas oferecidas pela instituição educacional (ROMANI; BORSZCZ, 2006, p. 30).

Com efeito, é louvável afirmar que

[...] o contexto em que a unidade está inserida representa o maior fator interferente na forma como as coleções serão gerenciadas, ou seja, as condições estruturais, a liberação de recursos, a presença de bibliotecário-gestor, as necessidades do público alvo e a cultura organizacional refletem nos processos de trabalho desenvolvidos em prol da formação e desenvolvimento das coleções (SANTA ANNA, 2015, p. 550).

Vergueiro (1993) discorre acerca das diferentes visões relatadas na literatura sobre a forma como as coleções são gerenciadas em diferentes modalidades de bibliotecas, tais como: nas públicas, universitárias, escolares e especializadas: para alguns teóricos, o processo deve ser semelhante e não sofrer alterações nas diversas tipologias de bibliotecas; para outros autores, cada biblioteca adotará procedimentos diferentes, tendo em vista a atender demandas específicas.

Vergueiro (1993) acredita que a segunda suposição seja mais evidente, ou seja, o processo de formar e desenvolver coleções ocorre de diferentes formas, considerando o contexto de cada biblioteca e suas organizações mantenedoras. Para esse autor: “[...] tudo parece indicar que o desenvolvimento de coleções precisa necessariamente ser tratado de maneira específica a cada tipo de biblioteca em que vier a ocorrer, uma vez que o processo tende a variar de acordo com as finalidades das instituições em que acontece" (VERGUEIRO, 1993, p. 19).

Por fim, o autor reforça que a questão do desenvolvimento de coleções não é enfocada da mesma maneira em todas as bibliotecas. Considera esse autor que essa parece ser uma consequência lógica da própria diversidade das instituições, que vão abranger características de acervo, usuário e meio ambiente onde se localizam (VERGUEIRO, 1993).

Considerando a afirmação descrita por Vergueiro (1993), de que cada modalidade de biblioteca estabelece diferentes formas de gerenciar suas coleções, tese essa que refuta a opinião de alguns autores internacionais, a seguir, por meio dos procedimentos metodológicos, apresentam-se os resultados oriundos do estudo de campo realizado em diferentes modalidades de biblioteca. 


\section{MÉTODO DA PESQUISA}

A metodologia estabelecida para nortear este estudo considerou a taxonomia estabelecida por Vergara (2007), a qual delimita que as pesquisas científicas sejam caracterizadas levando-se em conta os meios utilizados e os fins a que se destinam.

Quanto aos meios, o estudo sustentou-se na pesquisa bibliográfica, em que foi realizada em artigos publicados em revistas científicas da área de Ciência da Informação e Biblioteconomia, como também livros impressos e eletrônicos dessa mesma área. O objetivo dessa modalidade de pesquisa é levantar fundamentos teóricos que justifiquem e confirmem os dados coletados a partir da pesquisa de campo.

Quanto aos fins, a pesquisa caracterizou-se como de campo, uma vez que se visitou quatro diferentes modalidades de bibliotecas, com o intuito de analisar como as atividades de formar e desenvolver coleções eram realizadas. Investigou-se a realidade das seguintes modalidades de bibliotecas: pública, escolar, especializada e universitária.

O instrumento utilizado para coleta de dados foi a entrevista aberta realizada com o bibliotecário gestor de cada unidade de informação analisada. Utilizou-se roteiro estruturado previamente, contemplando sete perguntas que nortearam o diálogo entre entrevistado e entrevistador. De modo geral, as perguntas abarcaram diferentes aspectos relativos à gestão de coleções bibliográficas, tais como: organização das coleções, setor responsável, etapas do processo de formação e desenvolvimento de coleções, estudo de usuários, política, critérios para seleção e descarte/remanejo.

\section{RESULTADOS E DISCUSSÃO}

Após coleta dos dados, eles foram agrupados, separadamente, em quadros, a fim de facilitar a análise comparativa entre as diferentes modalidades de biblioteca. Cada quadro, a seguir, apresenta a pergunta realizada e a resposta de cada uma das bibliotecas investigadas.

A primeira pergunta do roteiro referiu-se à estruturação das coleções que formam o acervo da biblioteca. Observou-se, a partir das respostas, que os acervos estão compostos por coleções das mais diferenciadas, sendo comum a todos os acervos, a coleção de referência, livros, periódicos e multimeios (quadro 1). 


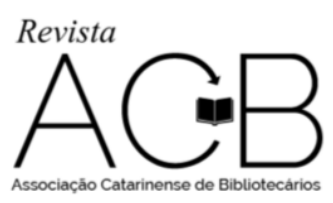

Quadro 1 - Coleções que formam o acervo bibliográfico da unidade

\begin{tabular}{|c|c|c|c|c|}
\hline Pergunta & B. Escolar & Especializada & Universitária & Pública \\
\hline $\begin{array}{l}\text { Como estão } \\
\text { divididas as } \\
\text { coleções no } \\
\text { acervo? }\end{array}$ & $\begin{array}{l}\text { Coleção de livros } \\
\text { infantis, livros } \\
\text { juvenis, história } \\
\text { em quadrinhos, } \\
\text { enciclopédias, } \\
\text { atlas e } \\
\text { dicionários, além } \\
\text { da coleção de } \\
\text { DVDs } \\
\text { pedagógicos }\end{array}$ & $\begin{array}{l}\text { Coleção de livros, } \\
\text { periódicos, } \\
\text { referência, } \\
\text { multimeios e obras } \\
\text { raras }\end{array}$ & $\begin{array}{l}\text { Coleções didáticas, } \\
\text { obras de referência, } \\
\text { multimeios e obras } \\
\text { raras }\end{array}$ & $\begin{array}{l}\text { Obras gerais, infanto } \\
\text { juvenil, coleções } \\
\text { escritos locais e setor } \\
\text { de obras em Braille }\end{array}$ \\
\hline
\end{tabular}

Fonte: dados da pesquisa (2016).

Refletindo acerca da divisão dos acervos, nota-se que todos agrupam os itens, com características semelhantes ou relacionais em diferentes grupos, denominados de coleções. Isso facilita, obviamente, o trabalho de busca e localização do item nas estantes. Cada uma adota uma forma de divisão diferente, devido às específicas literaturas que oferecem. No entanto, cabe destacar que, apenas as bibliotecas universitárias e especializadas adentram-se à divisão proposta por Miranda (1978) em que sugere como principais divisões de um acervo: coleção de referência, coleção de lastro (básica), coleção didática e literatura corrente.

A respeito do setor que realiza os trabalhos relacionados à formação e desenvolvimento do acervo, duas bibliotecas, escolar e pública, disseram que não há setor específico delimitado, sendo essas atividades realizadas pelos profissionais que fazem a catalogação dos itens. Já na biblioteca especializada e universitária, há setores reservados para realização dessas atividades (quadro 2).

Quadro 2 - Setor específico para realização das atividades de formação e desenvolvimento do acervo

\begin{tabular}{|c|c|c|c|c|}
\hline Pergunta & B. Escolar & Especializada & Universitária & Pública \\
\hline $\begin{array}{c}\text { Há um setor } \\
\text { específico }\end{array}$ & Não & Sim & Sim & \\
responsável pelo \\
processo FDC?
\end{tabular}

Fonte: dados da pesquisa (2016).

Sobre a questão do espaço ou setor específico para realizar as atividades de formação e desenvolvimento das coleções, consideramos de fundamental importância haver esse espaço. Para Vergueiro (1993), esse setor deveria existir em qualquer modalidade de biblioteca, assim como ocorre com o setor de tratamento do acervo. De acordo com os dados obtidos, das quatro bibliotecas analisadas, apenas a universitária e especializada delimitam um espaço para formar e desenvolver seus acervos.

Em seguida, perguntou-se se as atividades de formar e desenvolver coleções eram agrupadas em etapas, o que afere a consolidação de um processo de trabalho. Notou-se, com base nas respostas obtidas, que apenas na biblioteca pública não há etapas. Na biblioteca especializada e universitária, delimitam-se cinco etapas, enquanto que na escolar, há presença de quatro etapas (quadro 3). 
Quadro 3 - Quantidade de etapas nas atividades de formar e desenvolver coleções

\begin{tabular}{|c|c|c|c|c|}
\hline Pergunta & B. Escolar & Especializada & Universitária & Pública \\
\hline $\begin{array}{c}\text { Quantas etapas } \\
\text { contemplam o } \\
\text { processo FDC? }\end{array}$ & Quatro & Cinco & Cinco & \\
\hline
\end{tabular}

Fonte: dados da pesquisa (2016).

No que diz respeito às etapas no processo de FDC, a literatura, através dos modelos teóricos, recomenda etapas específicas. Devido à abrangência do processo, entendemos que o Modelo de Evans seja mais adequado, tendo em vista tornar a unidade um organismo em crescimento e sistêmico. Esse modelo dispõe de seis etapas: estudo comunidade, política, seleção, aquisição, desbastamento e avaliação (VERGUEIRO, 1993).

Ao dividir as atividades em etapas, estamos considerando os serviços como processuais, o que vai ao encontro do que Vergueiro (1993), Weitzel (2006) e Santa Anna (2015) consideram, ao apontar a processualidade como principal característica nas atividades de formar e desenvolver coleções bibliográficas.

Não resta dúvida de que, ao delimitar etapas e inter-relacioná-las estamos facilitando o trabalho das equipes, uma das preocupações dos modernos modelos de gestão, uma vez que evita sobrecarga de trabalho e facilita a tramitação dos fluxos de trabalho e do compartilhamento de informações durante a tramitação das atividades.

Embora não tenha sido direcionada pergunta sobre o porquê da divisão ou não em etapas, acredita-se que, de acordo com a realidade de muitas bibliotecas brasileiras, sobretudo as públicas e escolares, a escassez de mão de obra representa um grande entrave, conforme discorreu a pesquisa de Almeida Junior (1997, 2013).

Ao indagar a respeito do método que utilizam para conhecer as necessidades dos usuários, as respostas foram bem similares, sendo que as unidades utilizam de relatórios de empréstimos ou estatísticas de uso a fim de conhecer os itens mais procurados pelos usuários (quadro 4).

\begin{tabular}{|c|c|c|c|c|}
\hline Pergunta & B. Escolar & Especializada & Universitária & Pública \\
\hline $\begin{array}{l}\text { Como conhecem as } \\
\text { necessidades dos } \\
\text { usuários? Realizam } \\
\text { que tipo de estudo? }\end{array}$ & $\begin{array}{l}\text { Relatórios de } \\
\text { empréstimos }\end{array}$ & $\begin{array}{l}\text { Estatística de uso, } \\
\text { relatórios e pesquisa via } \\
\text { portal eletrônico }\end{array}$ & $\begin{array}{l}\text { Lista de sugestões e } \\
\text { análise dos planos de } \\
\text { disciplinas }\end{array}$ & $\begin{array}{c}\text { Relatórios de } \\
\text { empréstimos. Lista de } \\
\text { sugestões }\end{array}$ \\
\hline
\end{tabular}

Fonte: dados da pesquisa (2016).

Quanto ao estudo da comunidade ou de usuários, essa tarefa é de fundamental importância para a gestão das coleções, além de viabilizar êxito aos produtos e serviços oferecidos pelas bibliotecas (FIGUEIREDO, 1993). Os dados confirmam que nenhuma biblioteca faz estudo de usuário através de 


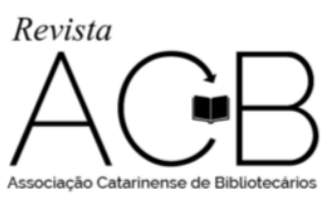

pesquisa aplicada, utilizando de instrumento de coletas de dados, como questionário e entrevista. As referidas unidades realizam levantamento, através de relatórios de empréstimos e estatísticas de uso.

Os dados obtidos nessa questão confirmam que as unidades utilizam de forma superficial das diferentes modalidades de estudos de usuários, conforme demonstrado em grande parte da literatura. Para Vergueiro (2010) e Figueiredo (1993), embora as estatísticas de uso e frequência à biblioteca sejam instrumentos avaliativos e que demonstram algumas necessidades, o perfil da comunidade usuária pode ser adquirido por meio de estudos mais aprofundados, como através do uso de entrevistas, coletando dados acerca da opinião/percepção do usuário quanto aos serviços e produtos biblioteconômicos oferecidos.

Assim, os estudos quantitativos e principalmente os qualitativos tornam necessários uma vez que analisam aspectos cognitivos que demonstram a necessidade do usuário e seu comportamento ao utilizar os produtos e serviços oferecidos pelas unidades de informação (WILSON, 2000).

A quinta pergunta do roteiro questionou a respeito da política de formação e desenvolvimento de coleções, indagando se as unidades possuem esse documento. De acordo com os dados obtidos, em apenas duas bibliotecas, especializada e universitária, há presença deste documento (quadro 5).

Quadro 5 - A presença da política de desenvolvimento de coleções nas bibliotecas investigadas

\begin{tabular}{|c|c|c|c|c|}
\hline Pergunta & B. Escolar & Especializada & Universitária & Pública \\
\hline $\begin{array}{c}\text { Possuem política } \\
\text { de FDC? }\end{array}$ & Não & Sim & Sim & $\begin{array}{c}\text { Não. Apenas possui } \\
\text { manual de } \\
\text { procedimentos para } \\
\text { recebimento de } \\
\text { doações }\end{array}$ \\
\hline
\end{tabular}

Fonte: dados da pesquisa (2016).

Considera-se como uma realidade preocupante às bibliotecas que não possuem a presença da política, pois esse é o documento que permeia as atividades realizadas, confere segurança nas decisões a serem tomadas, o que proporciona respaldo ao trabalho do profissional, assim como defendeu Santa Anna (2014).

No entendimento de Miranda (2007a), para a formação e expansão do acervo, a biblioteca deve estabelecer sua política de desenvolvimento de coleções que será materializada em documento, no qual serão levadas em consideração, dentre outros, os seguintes dados essenciais: os objetivos da biblioteca, o estado atual da coleção, as necessidades informacionais da comunidade a ser servida, orçamentos e outros recursos informacionais disponíveis.

Em linhas gerais, a literatura de formação e desenvolvimento de coleções é unânime ao garantir a necessidade e importância da política para nortear os fazeres dos profissionais, pois além de uniformizar as atividades, ela afere respaldo legal quanto ao processo decisório (MIRANDA, 2007a; VERGUEIRO, 2010; WEITZEL, 2006). 
No que se refere à etapa da seleção, investigou-se acerca dos principais critérios que são utilizados para que os itens sejam selecionados. Novamente, apenas a biblioteca especializada e universitária adotam critérios, enquanto as demais não os realizam (quadro 6).

Quadro 6 - Critérios utilizados para seleção dos materiais a serem incorporados ao acervo

\begin{tabular}{|c|c|c|c|c|}
\hline Pergunta & B. Escolar & Especializada & Universitária & Pública \\
\hline $\begin{array}{c}\text { Adotam critérios } \\
\text { para selecionar, } \\
\text { adquirir e } \\
\text { descartar } \\
\text { materiais? }\end{array}$ & Não & $\begin{array}{l}\text { Sim. Qualitativo: } \\
\text { adequação aos } \\
\text { objetivos da } \\
\text { instituição, } \\
\text { atualidade, } \\
\text { autoridade, } \\
\text { qualidade técnica e } \\
\text { editorial, demanda } \\
\text { pelos usuários e } \\
\text { questão de custo } \\
\text { benefício }\end{array}$ & $\begin{array}{c}\text { Sim. Material } \\
\text { atualizado. Material } \\
\text { recomendado pelos } \\
\text { usuários }\end{array}$ & $\begin{array}{l}\text { Não. Apenas há } \\
\text { critérios no } \\
\text { recebimento de } \\
\text { doações. O material } \\
\text { deve ser enviado por } \\
\text { email para análise do } \\
\text { bibliotecário. Caso } \\
\text { seja material } \\
\text { pertinente, o doador } \\
\text { poderá trazê-lo. Há } \\
\text { critérios também para } \\
\text { descarte, em caso de } \\
\text { material desatualizado }\end{array}$ \\
\hline
\end{tabular}

Fonte: dados da pesquisa (2016).

Analisando os critérios utilizados para seleção de itens informacionais, percebemos vários critérios adotados pela biblioteca especializada, pouca criteriosidade na biblioteca universitária e ausência de critérios nas bibliotecas escolar e pública. A pública adota critérios para seleção apenas de doações. Curioso mencionar que na especializada, adotam-se critérios qualitativos, como: atualidade, autoridade, qualidade técnica e editorial, demanda pelos usuários, dentre outros. Esses critérios viabilizam a escolha dos materiais, auxiliando a equipe de seleção (VERGUEIRO, 2010).

Adotar critérios compreende uma atividade imprescindível, pois eles constituem a via mestra para se consolidar um acervo com qualidade, que atenda necessidades demandadas. Assim, a literatura exige a presença da etapa da seleção, sendo que Vergueiro (2010) elucida diversos critérios que podem ser adotados, tais como: a atualidade, a conservação, o preço, a necessidade do usuário, dentre muitos outros.

Convém mencionar, outrossim, que a seleção é um momento de decisão, onde se determina os itens que irão compor o acervo, através de critérios pré-estabelecidos por uma comissão responsável por essa atividade em questão. Na visão do teórico Ranganathan (2009), a seleção é uma atividade que ocorre diariamente, onde os itens selecionados estão de acordo com as exigências dos usuários, do movimento editorial e dos recursos disponíveis. Os materiais selecionados também devem estar de acordo com os objetivos da instituição mantenedora.

Percebe-se a importância que a etapa da seleção e o estabelecimento de critérios exercem na formação e desenvolvimento do acervo, haja vista, sistematizar coleções atualizadas, em bom estado de conservação, 


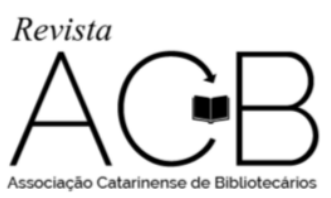

por conseguinte, que possam ser utilizadas pelos usuários (VERGUEIRO, 2010). Portanto, as bibliotecas que não realizam essa etapa com criteriosidade tendem a consolidar coleções abarrotadas e inutilizáveis.

A última pergunta do roteiro de entrevista indagou acerca da realização de descarte ou remanejo, processos esses os quais visam eliminar itens da coleção ou transferi-los para outros locais fora do acervo corrente, respectivamente (MACIEL; MENDONÇA, 2006).

De acordo com os dados obtidos, nota-se que em três bibliotecas realizam-se essas atividades e apenas em uma não se realizam quaisquer ações voltadas ao descarte ou remanejo de materiais (quadro 7).

\begin{tabular}{|c|c|c|c|c|}
\multicolumn{5}{|c}{ Quadro 7 - Descarte e remanejo de materiais nas bibliotecas investigadas } \\
\hline Pergunta & B. Escolar & Especializada & Universitária & Pública \\
\hline É permitido & Não & Sim. Tanto descarte & Sim. Somente & Sim. Somente aqueles \\
descartar & & $\begin{array}{c}\text { quanto remanejo, } \\
\text { conforme critérios } \\
\text { quando estão muito } \\
\text { destabelecidos na }\end{array}$ & $\begin{array}{c}\text { qualizados } \\
\text { desatualizados. }\end{array}$ \\
materiais ou & & política & & \\
remanejá-los & & & & \\
quando constatada & & & & \\
a pouca & & & & \\
utilização? & & & & \\
\hline
\end{tabular}

Fonte: o autor (2016).

A leitura do quadro acima demonstra que a biblioteca escolar não realiza remanejo ou descarte de itens bibliográficos; a pública e universitária realiza apenas descartes de obras desatualizadas; já a especializada, por possuir uma política com critérios estabelecidos, realiza o descarte e remanejo, conforme o atendimento aos critérios instituídos. Aqui, novamente, explica-se o valor que a política de formação e desenvolvimento de coleções pode proporcionar, garantindo uniformidade às atividades e segurança das decisões tomadas pelo profissional (MIRANDA, 2007a).

Importante frisar que a prática de descartar materiais tornar-se-ia mais confiável e segura se houvesse a adoção de critérios, devidamente oficializados na política, por conseguinte, garantiria respaldo legal às decisões a serem tomadas. Esse fato garantiria cientificidade às atividades, pois o profissional não agiria de forma aleatória, mas comprovaria/justificaria o porquê de suas atitudes e decisões (SANTA ANNA, 2014).

Torna-se um tanto contraditório e perigoso adotar ações de descarte de materiais se não há justificativa do quê e porquê eliminar. A biblioteca pública analisada mencionou que realiza descartes de materiais desatualizados, sem conter esse procedimento registrado na política. Isso pode comprometer a segurança do trabalho do profissional, uma vez que essa ação não está oficialmente/legalmente instituída na unidade de informação.

Com efeito, não resta dúvida de que a presença da política e do estabelecimento de critérios às atividades de formar e desenvolver coleções torna-se imprescindível, pois assegura o trabalho profissional, 


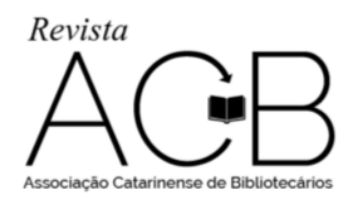

assim como viabiliza sucesso das atividades realizadas em prol da qualidade das coleções bibliográficas existentes nos acervos.

Por fim, analisando cada uma das perguntas e as comparando com as práticas realizadas no cotidiano das quatro unidades investigadas, percebe-se que há muita diversidade quanto às atividades de formar e desenvolver coleção. Isso, em um primeiro momento pode ser explicado pelo fato das instituições adentrarem-se à cultura organizacional, ou seja, os costumes de uma empresa são fatores interferentes para que ações específicas sejam realizadas em seu contexto.

\section{CONSIDERAÇÕES FINAIS}

Como resultados de pesquisa, constatou-se a afirmação de Vergueiro (1993) quando menciona que em cada modalidade de biblioteca, ou em cada contexto organizacional/institucional, os procedimentos que sustentam o processo de formar e desenvolver coleções são diferenciados. Este estudo analisou as diferentes atividades que contemplam o processo de formar e desenvolver coleções em quatro diferentes modalidades de bibliotecas, portanto, considerando a proposta inicial de pesquisa.

Entende-se que o contexto organizacional é um dos fatores mais interferentes na forma como as coleções bibliográficas são formadas e desenvolvidas. Mesmo havendo recomendações por parte da literatura, assim como proposições estabelecidas a partir de pesquisas realizadas, as atividades de formar e desenvolver coleções não são semelhantes entre as quatro bibliotecas analisadas. Constatou-se que boa parte das atividades realizadas pela biblioteca especializada e universitária está condizente com as recomendações propostas pela literatura, enquanto que na biblioteca pública e escolar, a realidade é bem destoante.

Concluiu-se que, a padronização dos processos de trabalho e o crescimento racional do acervo, atendendo as necessidades demandadas e garantindo segurança às atividades profissionais, torna-se mais provável de serem alcançados se houver uma política de formar e desenvolver coleções para nortear e fundamentar as decisões e procedimentos realizados. As bibliotecas com ausência de política carecem de um instrumento normativo para embasar as decisões tomadas, bem como seguir procedimentos padronizados de organização dos documentos, enquanto que as bibliotecas com política, como a especializada e universitária, tendem a estruturar suas coleções com criteriosidade, o que pode viabilizar maior organização, controle e gestão do acervo. Infere-se que, mesmo sendo influenciadas pelo contexto organizacional, faz-se imprescindível o estabelecimento de uma política de formação e desenvolvimento de coleções, de modo a facilitar a gestão das coleções e o desenvolvimento equilibrado do acervo. 


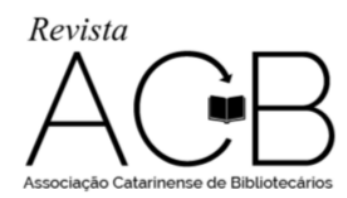

Os procedimentos metodológicos adotados neste estudo não permitem constatar o motivo que proporciona a não adoção das recomendações teóricas na realidade das bibliotecas analisadas. Portanto, recomenda-se a realização de futuras pesquisas, haja vista detectar os problemas rotineiros enfrentados por essas bibliotecas, os quais afetam a formação e desenvolvimento do acervo. Também se torna pertinente a realização de diagnósticos e projetos nessas bibliotecas, com o intuito de estabelecer proposições de melhoria aos processos de formar e desenvolver coleções.

\section{REFERÊNCIAS}

ALMEIDA JÚNIOR, Oswaldo Francisco de. Sociedade e biblioteconomia. São Paulo: Polis, 1997.

Biblioteca pública: avaliação de serviços. Londrina: Eduel, 2013.

CORREA, Elisa; SANTOS, Luana Carla Moura dos. De formação e desenvolvimento de coleções para gestão de estoques de informação: um panorama da mudança terminológica no Brasil. Revista Digital de Biblioteconomia e Ciência da Informação, Campinas, SP, v. 13, n. 2, p. 342-354, maio/ago. 2015.

Disponível em: <periodicos.sbu.unicamp.br/ojs/index.php/rdbci/article/view/8634631>. Acesso em: 24 ago. 2015.

FIGUEIREDO, Nice Menezes de. Desenvolvimento e avaliação de coleções. Rio de Janeiro: Rabiskus, 1993.

MACIEL, Alba Costa; MENDONÇA, Marília Alvarenga Rocha. Bibliotecas como organizações. Rio de Janeiro: Interciência; Niterói: Intertexto, 2006.

MIRANDA, Antônio. Biblioteca universitária no Brasil: reflexões sobre a problemática. Brasília: MEC, 1978.

MIRANDA, Ana Cláudia Carvalho de. A política de desenvolvimento de coleções no âmbito da informação jurídica. In: PASSOS, Edilenice (Org.). Informação jurídica: teoria e prática. Brasília: Thesaurus, 2004.

. Desenvolvimento de coleções em bibliotecas universitárias. Revista Digital de Biblioteconomia e Ciência da Informação, Campinas, v. 4, n. 2, p. 1-19, jan./jun. 2007a. Disponível em:

<http://www.sbu.unicamp.br/seer/oj s/index.php/rbci/article/view/367/246 >. Acesso em: 10 mar. 2015.

. Formação e desenvolvimento de coleções em bibliotecas especializadas. Informação e Sociedade:

Estudos, João Pessoa, v.17, n.1, p.87-94, jan./abr., 2007b. Disponível em:

<http://www.ies.ufpb.br/ojs/index.php/ies/article/view/463/1468>. Acesso em: 29 fev. 2016.

RANGANATHAN, Shiyali Ramamrita. As cinco leis da biblioteconomia. Brasília: Briquet de Lemos/Livros, 2009.

ROMANI, Cláudia; BORSZCZ, Iraci (Org.). Unidades de informação: conceitos e competências. Florianópolis: UFSC, 2006. 
SANTA ANNA, Jorge. Desenvolvimento de coleções no sistema de biblioteca da Ufes: comparativo entre os modelos teóricos de Evans e Baughman e proposta de adequação ao modelo de Evans. In: SEMINÁRIO NACIONAL DE BIBLIOTECAS UNIVERSITÁRIAS, 18. Anais eletrônicos... Belo Horizonte: UFMG, 2014. Disponível em: 〈https://www.bu.ufmg.br/snbu2014/wp-content/uploads/trabalhos/271-1821.pdf >. Acesso em: 18 fev. 2016.

Desafios para a gestão de estoques de informação frente às coleções em diferentes contextos.

Revista ACB: Biblioteconomia em Santa Catarina, Florianópolis, v. 20, n. 3, p. 550-566, set./dez., 2015. Disponível em: < http://revista.acbsc.org.br/racb/article/view/1092/pdf>. Acesso em: 17 fev. 2016.

VERGARA, Sylvia. Projetos e Relatórios de Pesquisa em Administração. São Paulo: Atlas, 2007.

VERGUEIRO, Waldomiro. Desenvolvimento de coleções. São Paulo: Polis: APB, 1989.

Desenvolvimento de coleções: uma nova visão para o planejamento de recursos informacionais.

Ciência da Informação, Brasília, v. 22, n. 11, p. 13-21. jan./abr. 1993. Disponível em:

<http://revista.ibict.br/ciinf/index.php/ciinf/article/viewFile/1208/849>. Acesso em: 15 abr. 2014.

2010.

Seleção de materiais de informação: princípios e técnicas. 3. ed. Brasília, DF: Briquet de Lemos,

WEITZEL, Simone da Rocha. Elaboração de uma política de desenvolvimento de coleções em

bibliotecas universitárias. Rio de Janeiro: Interciência: Intertexto, 2006.

WILSON, Thomas. Recent trends in user studies: action research and qualitative methods. Information

Research, v. 5, n. 3, apr. 2000.

WORTMAN, Willian. Collection Development: background and pricinples. Chicago: ALA, 1989. 


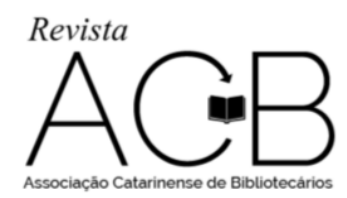

O contexto organizacional e seus reflexos no desenvolvimento de coleções: um estudo à luz das diferentes modalidades de bibliotecas - Jorge Santa Anna

\title{
ORGANIZATIONAL CONTEXT AND ITS CONSEQUENCES IN THE COLLECTIONS OF DEVELOPMENT: A STUDY IN THE LIGHT OF ARRANGEMENTS OF DIFFERENT LIBRARIES
}

\begin{abstract}
Training and development of collections in libraries is a process that has been changing over time and should be managed with criteriosidade, given enable quality to the materials incorporated into the library collections. While there a number of recommendations proposed by the literature as to the form of activities and to develop collections, the reality of libraries often divergent in some respects. Therefore, this study aims to analyze the activities imbued with this process, carried out in four different libraries, covering the modalities: public, school, specialized and university. It is intended, through comparative data analysis, presenting the dispersion procedures performed in the formation and development of the collections of their libraries analyzed. By interviewing managers of these units, it was found that in each library mode, or in each context, the procedures that underpin the process of forming and developing collections are different, and, most of the activities of the specialized library and university it is consistent with the recommendations proposed in the literature, while the public and school library, the reality is quite jarring. It is inferred that even being influenced by the organizational context, it makes indispensable the establishment of a policy to train and develop collections, in order to facilitate the management of collections and the balanced development of the acquis.
\end{abstract}

Keywords: Bibliographic Collection. Training and development of collections. Collections management. Collection development policy.

RECEBIDO EM: 29-07-2016

ACEITO EM: 10-02-2017 